not, in 1934, "President of the Swann galleries." He was, at that time, a bookseller and the Swann galleries, with which he never had any connection, was not in existence. These are minor blemishes on an interesting contribution.-David A. Randall, The Lilly Library, Indiana University.

\section{An Introduction to Scientific Research in} Librarianship. By Herbert Goldhor. Final Report, Project No. 7-1271, Contract No. OEC-1-7-071217-5113. U.S. Department of Health, Education and Welfare, Office of Education, Bureau of Research. Distributed by Illini Union Bookstore.

This brief survey of research methods is designed for doctoral students in librarianship and for practicing librarians who would like to become more critical consumers of research. Dr. Goldhor begins with a discussion of the basic approaches to knowledge and truth, and proceeds to describe and evaluate the methods used in the approach which he defines as scientific research. The fulfillment of such a broad assignment in the space of 201 pages results in exactly that which is suggested by the title-an introduction. This is neither a textbook nor a manual, but an exposition for the beginner on the meaning, goals, and limitations of scientific research in librarianship.

With topics ranging from historical research to statistical inference, the treatment is much too general to aid the student in developing practical methodological or critical skills. Dr. Goldhor's book rather serves to point out the techniques which the student should master in order to become an accomplished researcher. It also aims at developing a realistic attitude towards research, including an understanding that awesome patience is required to perform it properly, and an appreciation of the fact that no single study is likely to resolve any significant research question. While there are some solid guidelines on how to identify a researchable topic and how to approach the planning and design of a study, the serious student would need to go beyond Goldhor to the more detailed and technical works listed in his bibliographies. For a general text, this reviewer's preference is Fred Kerlinger's Foundations of Behavioral Research.

There are several notable and welcome emphases in Goldhor's work. Planning and design of the research study is given equal treatment with data collection and analysis. Hypothesis testing is emphasized. While Goldhor's idealistic description of a hypothesis as a statement of relationship which is "universal, invariant and causal" will find only rare application in librarianship, the use of less ambitious hypotheses as focusing devices would improve many studies in librarianship. The frequent lack of a formal hypothesis statement in library research is related to the widespread use of inadequate designs.

Goldhor also emphasizes theory-oriented research. The development of theory is necessary to amend perhaps the major deficiency of library research in general, the fact that ". . . most library research consists of single studies whose results are not cumulative." If a unified, cumulative research effort is to be sustained in any area of librarianship, it will occur only when some form of theory, good or bad, has been posited. For that reason Goldhor's emphasis on a theoretical orientation is precisely what is needed at this point. It serves as another reminder that research in librarianship still has a long way to go. -Joe Hewitt, University of Colorado.

Magazines for Millions: The Story of Specialized Publications. By James L. C. Ford. Carbondale, Ill.: Southern Illinois University Press, 1969. 320p. \$11.75. (79-76187).

There is much in this book which will be of interest to librarians working with serials and to students and faculty in journalism and communications as well as to the lay reader concerning specialized magazines. It is a comprehensive study of the multimillion dollar business of publishing journals aimed toward the special interests of millions of readers. Mr. Ford's work is well organized and very readable -a difficult feat to accomplish as this type of material could easily end up in a form of bibliographic cataloging interspersed with statistics. Much of the information was 
gathered through personal interviews and the personal knowledge and editing experience of the author has made this an interesting and informative work.

Mr. Ford is a professor of journalism at Southern Illinois University, where he has been on the faculty since 1955 . He was formerly Dean of the School of Journalism at the University of Montana for twelve years. His career has included editorial positions and a stretch of service with the United Press International. The lucid delineation of special magazines found in this book reflects his experience and interest in this field.

The author has categorized specialized publications into nine groups and has devoted a chapter to each group. "The Affluent Home and Family" covers the multitude of home and garden magazines. "The Juvenile Revolution" outlines the magazines designed for younger readers from the primary level through the teens. "The Long, Leisurely Weekend" covers a gamut of popular magazines which feature crafts, hobbies, entertainment, and general leisure reading. "The Role of Religious Magazines" examines in some depth the publications of major denominational publishing houses. "The Giant Galaxy of Company Publications" covers the broad scope of internal and external publication objectives within various companies. "The Voice of Industry" surveys the area covered by 2,600 industrial magazines. "The Siamese Twins-Business and Labor" includes such giants as U.S. News \& World Report, Business Week, UAW's Solidarity, and The International Teamster, along with many other titles and gives résumés of intent and statistical information pertinent to the degree of coverage. "Professions and Associations" examines special magazines in the fields of education, medicine, law, radio-television, motion pictures and photography, to name but a few. "Down on the Farm" cites the leaders in the field of farm magazines and gives information about them as well as about the regional aspects involved. Finally, the "Land of the Giants" examines those publications issued by such Herculean forces as the American Chemical Society, Hearst Corporation, Macfadden-Bartell Corporation, Standard Rate \& Data Service and others.
This volume adds another resource on the subject of magazine publishing, an area that has received but moderate attention by historians. Professor Ford has examined a number of titles in depth and has analyzed audiences to whom the journals are directed. His clear definitions of the various types of magazines encompassed in the phrase "specialized publications" adds significant value to this study. Interviews with editors, publishers, and executive personnel connected with the special publications field provide subjective information previously unavailable. Well-chosen illustrations, graphs and charts add much to the interest and understanding of the book.

I believe it would have been useful to have included in the main index a listing of all of the titles cited in the text, or to have included an appendix with such a listing. The main index does cite some titles under the various headings, such as "Labor Publications: Summaries of." Other than this approach, one must check the text to find specific titles.

Magazines for Millions will be at home alongside of the works of Frank Luther Mott, Theodore Peterson, Roland E. Wolseley and James Playsted Wood, since it provides a study in a major segment of magazine publishing which has been relatively neglected in the past.-William H. Huff, University of Illinois.

\section{BOOKS RECEIVED}

Note: The titles listed represent books received at the editorial office that may be of interest to academic librarians.

American Men of Science. Supplement 6. The Physical and Biological Sciences. 11th ed. (edited by the Jaques Cattell Press). New York: R. R. Bowker, 1970. 784p. \$25.00. (6-7326).

American National Standard for the $A b$ breviation of Titles of Periodicals. Sponsored by the Council of National Library Associations. New York: American National Standards Institute, Inc., 1970. 11p.

An Index to Bibliographies and Bibliographical Contributions: Relating to the 